\title{
Effects of Triazolam and Nifedipine Injections into the Medial Preoptic Area on Sleep
}

\author{
Wallace B. Mendelson, M.D. and Daniel Monti, M.D.
}

We have reported previously that microinjections of the meodiazepine (BZ) hypnotic triazolam into the medial proptic area (MPA) of the hypothalamus increase sleep in the rat. As a follow up to previous work, which has indicated that the dihydropyridine calcium channel Wocker, nifedipine, prevents sleep induction by an intraperitoneally administered $B Z$, we have now coinjoded nifedipine and triazolam into the MPA. It was found that nifedipine alone had no significant effects on sleep and prevented sleep induction by triazolam. There were no drug-specific effects on core temperature in any treatment condition. These data suggest that dihydropyridine-sensitive sites may be involved in the mechanism of sleep induction by BZs. [Neuropsychopharmacology 8:227-232, 1993]
ICY wORDS: Nifedipine; Triazolam; Benzodiazepines; Proptic area

Nthough there is a growing body of data on the mokevular actions of benzodiazepines (BZs) with the BZ/ gmma aminobutyric acid-a receptor complex, the neuroanatomic site(s) at which these compounds act to enhance sleep are poorly understood. In a series of studies in which the BZ hypnotic triazolam was microinjected into nuclei thought to be associated with sleep regulaion, we have previously observed that administration into the medial preoptic area (MPA) during the daytime enhances sleep, and no effect occurs after injecion into two nearby structures; this effect is prevented by the $B Z$ receptor blocker RO 15-1788 (Mendelson and Martin 1992). To further characterize this action of triazolam, we are exploring the possibility that the druginduced sleep enhancement may be mediated by altercions in cellular calcium channelactivity. This approach derives from observations that increased ${ }^{45} \mathrm{CA}^{++}$up-

From the Center for the Study of Sleep and Waking, State Univery of New York at Stony Brook, Stony Brook, New York.

Address correspondence to: Dr. Wallace Mendelson, Center for the Study of Sleep and Waking, State University of New York at Stony hook, University Hospital MR 120A, Stony Brook, New York, 117947139.

Received March 6, 1992; revised August 3, 1992; accepted August D. 1992. take into synaptosomes induced by low concentrations $(1 \mu \mathrm{m})$ of diazepam is prevented by the dihydropyridine calcium channel blocker, nifedipine (Mendelson at al. 1984a), and that in vivo intraventricular administration of nifedipine prevents sleep induction by systemically administered flurazepam (Mendelson et al. 1984b). Conversely, sleep induction by parenteral flurazepam is potentiated by Bay $\mathrm{K} 8644$, a dihydropyridine that increases uptake of ${ }^{45} \mathrm{CA}^{++}$into synaptosomes (Mendelson 1987). In the present study, we observed sleep and core temperature following coinjection of triazolam and nifedipine into the MPA of rats.

\section{METHODS}

Thisstudy had a modified Latin-square design in which all animals were given triazolam 0.25 and $0.5 \mu \mathrm{g}(0.73$ $\mathrm{nmol}$ and $1.46 \mathrm{nmol}$ ) and its vehicle, in combination with nifedipine $16 \mu \mathrm{g}(46 \mathrm{nmol})$ and its vehicle. Each animal received all six treatment combinations. All treatments and recordings were separated by 1 week. The study was performed on 15 male Sprague-Dawley albino rats weighing between 250 and $300 \mathrm{~g}$, purchased from Taconic Farms (Germantown, NY). After the surgical implantation of cannulae and electrodes (Mendelson and Martin 1992), the rats were housed individually in smooth-walled plastic cages for at least 1 week 
prior to use in a study. Lights were on from 8:00 A.M. until 8:00 P.M. The ambient temperature was maintained with at $26.25 \pm 0.06^{\circ} \mathrm{C}$; an analysis of variance (ANOVA) revealed no significant differences between ambient temperature across the treatment conditions.

Techniques for anesthesia and surgical implantation of cannulae have been described in detail in previous publications (Mendelson and Martin 1992). In summary, rats were placed in a Kopf stereotaxic apparatus with a mouth bar adjusted to provide a horizontal plane for the lambda and bregma. After a scalp incision was made and the skull exposed, holes were drilled at stereotactically determined locations. The dura was then gently disrupted at the holes and bilateral 24-gauge stainless-steel guide cannulae were lowered to $1 \mathrm{~mm}$ above the brain site of interest. The stereotaxic coordinates of the tip of the guide cannula (in $\mathrm{mm}$ ), derived originally from Paxinos and Watson (1986), and assessed from previous work, and pilot studies were as follows AP: -0.4 ; $\mathrm{ML}$ : +0.5; DV: -7.1.

During the same surgical procedure, four $0-80$ stainless-steel screws were implanted through the skull to serve as dural electroencephalographic (EEG) electrodes. These screws were connected to an Amphenol socket by short lengths of 0.010 -in. Teflon-coated, stainless-steel wire. The stripped ends of two other lengths of this wire were implanted in the neck musculature to act as electromyographic (EMG) electrodes and these were also connected to the Amphenol socket. Before releasing the rat from the stereotaxic apparatus, the entire assembly of cannulae, electrodes, and Amphenol socket was cemented in place with dental acrylic. The edges of the wound were then treated with an ointment containing bacitracin, polymyxin, and neomycin. Finally, the guide cannulae were occluded with 31-gauge stainless-steel stylets of matching length, and a protective plug was placed in the Amphenol socket.

To adapt the animals to the recording environment, they were placed in the recording chambers at 4:00 P.M. on the day before the experiment. At 10:00 A.M. the next morning, the stylet was removed from each guide cannula, and an injection cannula of 31-gauge stainlesssteel tubing was inserted so that the tip extended precisely $1 \mathrm{~mm}$ past the tip of the guide cannula into the brain. Triazolam (kindly supplied by the Upjohn Co., Kalamazoo, MI) or nifedipine (kindly supplied by Miles Pharmaceuticals, West Haven, CT), or vehicle was first warmed to $37^{\circ} \mathrm{C}$, and then injected from a $10-\mu \mathrm{l}$ Hamilton syringe through a length of PE 20 tubing attached to the injection cannula. The injection for each drug was given in a volume of $0.2 \mu \mathrm{l}$ of each side, administered over 1 minute, using a syringe pump, and the inner cannula was then left in place for 30 seconds. The volumes and infusion rate were derived from the work of Myers (1966), to minimize tissue damage and restrict diffusion of drug from the injection site. One syringe was used for each side, and injections were essentially simultaneous. Triazolam was dissolved in a 1:1 mi. ture of Emulphor polyoxyethylated vegetable oil and ethanol. Just prior to the injection, the solution ws diluted 10-fold with artificial cerebrospinal fluid (Mer delson and Martin 1992). All drug vehicles were trat passed through a Millipore Millex-HV $0.45-\mu \mathrm{m}$ filta. The total doses of triazolam for both sides combind were $0.25 \mu \mathrm{g}(0.73 \mathrm{nmol})$ and $0.5 \mu \mathrm{g}(1.46 \mathrm{nmol})$. Nifes pine was prepared by dissolving $40 \mathrm{mg}(115 \mu \mathrm{mol})$ $300 \mu$ l of a 1:1 mixture of polyethylene glycol and ethe nol, and diluting with $700 \mu \mathrm{l}$ of distilled water. Bilaterd injections of $0.2 \mu \mathrm{l}$ on each side were administered s described above, for a total dose of $16 \mu \mathrm{g}(46 \mathrm{nmol})$. Fot lowing the injection, the stylet was replaced and the study begun.

Following the injection of drug, each rat was plaod back in its testing chamber and a cable to a Grass Modd 78 polygraph was attached to the Amphenol connes. tor on the rat's headset. Three traces representing bifrontal EEG, frontooccipital EEG, and EMG were recorded for 2 hours for each rat. The paper speed ws $10 \mathrm{~mm} / \mathrm{sec}$ and the vertical deflection of the pen wa calibrated so that $1 \mathrm{~cm}$ signified an electrical potentit of $50 \mu \mathrm{V}$. After the recording, animals were retumed to their housing and subsequent tests of further drug treatment conditions were performed at weekly in tervals.

At the end of the study, a single investigator (who was unaware of the treatment condition) classified ead 30-second epoch as "waking," "nonrapid-eye move ment (nonREM) sleep," or "REM sleep" (Mendelsona al. 1974). The results were then tallied and reported in terms of parameters including total sleep time, sleep latency (time from drug injection until the frst throe consecutive 30-second epochs of sleep), intermittert waking time (waking time after initial sleep onset), RE. latency (time from sleep onset until the first two corr secutive epochs of REM sleep), nonREM sleep time, and REM sleep time (Mendelson et al. 1978). As our prepi ous study (Mendelson and Martin 1992) indicated ths drug-induced changes in sleep were largely confined to the first 2 hours after administration, we present dit for this period only.

After a rat underwent all the weekly drug trest ments and EEG recordings for a given experimental pio tocol, an injection of $400 \mathrm{mg} / \mathrm{kg}(1.61 \mathrm{mmol} / \mathrm{kg})$ of $w$ dium pentobarbital was given intraperitoneally and the animal was perfused transcardially as described preni ously (Mendelson and Martin 1992). The rat was the decapitated and the brain removed and stored in the formalin solution. Coronal brain sections $(48 \mu \mathrm{M})$ wer cut on a freezing microtome, mounted on slides, and stained with cresyl violet. The tip of the injection nula track was then localized by light microscopy. F ure 1 demonstrates the injection sites in all animale 

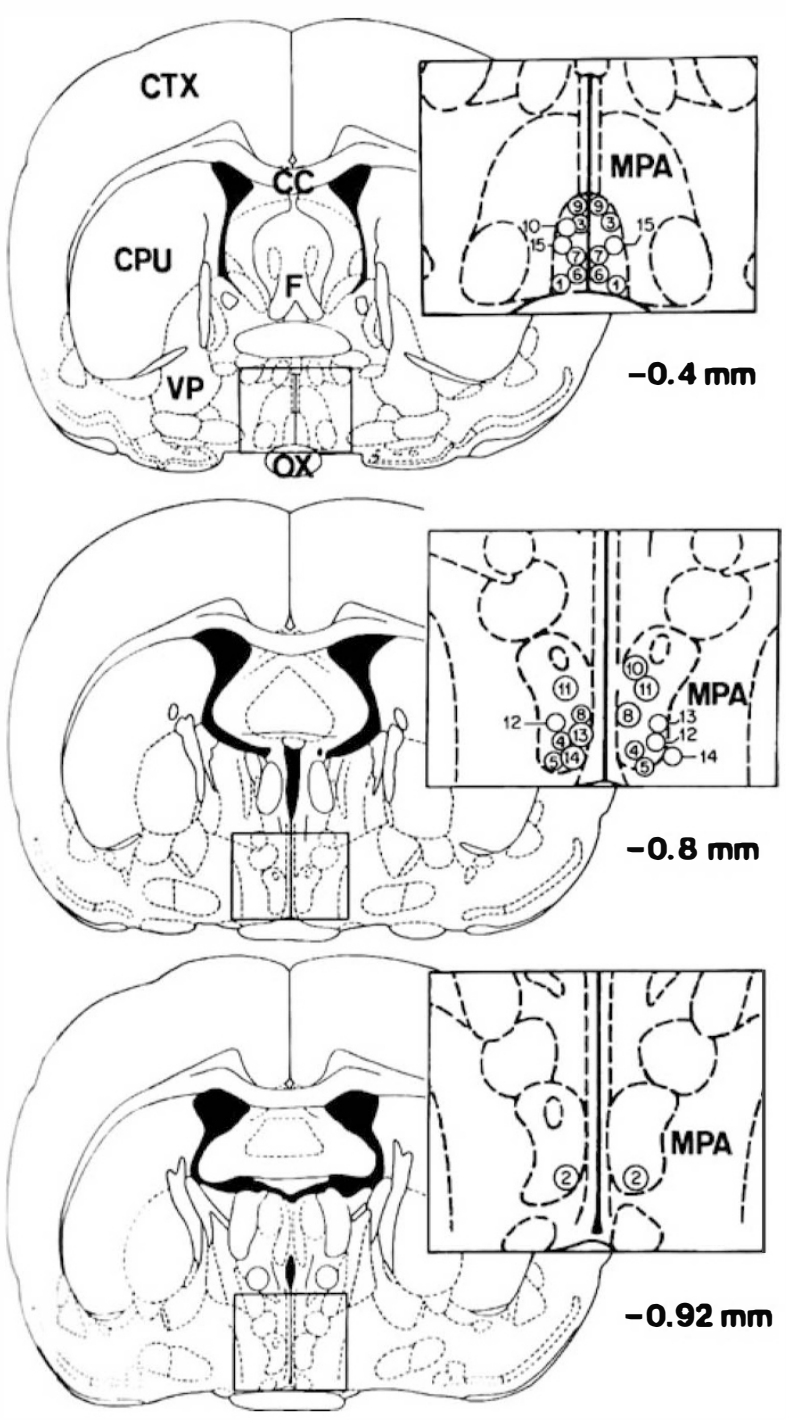

Figure 1. Injection sites of triazolam and nifedipine. Inset box details of MPA area, located immediately above OX. Numbers beneath the inset box represent the distance in millimeters posterior to bregma. Abbreviations: $\mathrm{AC}=$ anterior commissure; $\mathrm{CC}=$ corpus callosum; $\mathrm{CPU}=$ caudate putamen (striatum); $C T X=$ cerebral cortex; $F=$ fornix; $M P A=$ medial preopic area; $\mathrm{OX}=$ optic chiasm; and VP = ventral pallidum.

\section{Measurement of Core Body Temperature}

Core temperature was assessed by means of the MiniMitter system, which includes a transmitter implanted intraperitoneally at the time of the surgical placement of the EEGelectrodes. This transmitter sends out a signal that encodes temperature. A receiver is situated underneath each of the testing cages and the signal is decoded by an IBM PC microcomputer.

For each animal, temperature was recorded for a 20-minute baseline period before drug injection, and for 6 hours after injection. Measures of temperature induded mean temperature for the 1st and 2nd hours after drug injection, difference in temperature between
Table 1. Sleep Variables

\begin{tabular}{|c|c|c|c|}
\hline & Mean & SEM & $\underset{p<}{\text { Significance }}$ \\
\hline \multicolumn{4}{|c|}{ Sleep latency* } \\
\hline $\mathrm{VV}$ & 25.3 & 3.0 & NS \\
\hline VL & 15.6 & 2.0 & 0.001 \\
\hline $\mathrm{VH}$ & 12.4 & 1.9 & 0.001 \\
\hline DV & 25.5 & 2.3 & NS \\
\hline DL & 20.2 & 1.6 & NS \\
\hline DH & 21.7 & 2.2 & NS \\
\hline \multicolumn{4}{|c|}{ Total sleep time** } \\
\hline VV & 62.4 & 2.6 & NS \\
\hline VL & 73.2 & 4.1 & 0.01 \\
\hline VH & 75.7 & 2.9 & 0.001 \\
\hline DV & 69.5 & 3.4 & NS \\
\hline DL & 76.1 & 2.0 & 0.001 \\
\hline DH & 68.3 & 3.2 & NS \\
\hline \multicolumn{4}{|c|}{ nonREM sleep ${ }^{\star \star \star}$} \\
\hline $\mathrm{VV}$ & 57.7 & 2.7 & NS \\
\hline VL & 70.0 & 4.0 & 0.001 \\
\hline VH & 70.2 & 2.4 & 0.001 \\
\hline DV & 65.5 & 2.9 & 0.03 \\
\hline DL & 70.6 & 1.7 & 0.001 \\
\hline $\mathrm{DH}$ & 63.2 & 3.3 & NS \\
\hline \multicolumn{4}{|c|}{ REM sleep ${ }^{\star \star \star \star}$} \\
\hline VV & 5.1 & 0.8 & NS \\
\hline VL & 3.7 & 0.8 & NS \\
\hline VH & 7.3 & 1.0 & NS \\
\hline DV & 4.0 & 1.0 & NS \\
\hline $\mathrm{DL}$ & 5.5 & 0.6 & NS \\
\hline $\mathrm{DH}$ & 4.5 & 1.0 & NS \\
\hline \multicolumn{4}{|c|}{ Wake time } \\
\hline VV & 32.5 & 1.9 & NS \\
\hline VL & 31.3 & 3.4 & NS \\
\hline VH & 32.9 & 2.9 & NS \\
\hline DV & 24.8 & 2.1 & NS \\
\hline DL & 24.9 & 2.4 & NS \\
\hline $\mathrm{DH}$ & 30.6 & 3.5 & NS \\
\hline \multicolumn{4}{|c|}{ REM latency } \\
\hline $\mathrm{VV}$ & 68.4 & 12.2 & NS \\
\hline VL & 92.5 & 20.5 & NS \\
\hline VH & 67.5 & 16.4 & NS \\
\hline DV & 54.5 & 12.3 & NS \\
\hline DL & 33.2 & 4.7 & NS \\
\hline DH & 38.3 & 9.6 & NS \\
\hline
\end{tabular}

Treatment Effect (ANOVA): * df 5, 70, $\mathrm{F}=7.499949, \mathrm{p}<0.00001$; ${ }^{\star \star}$ df $5,70, \mathrm{~F}=3.323156, \mathrm{p}<0.01 ;{ }^{\star \star \star}$ df $5,70, \mathrm{~F}=3.973966$, $\mathrm{p}<0.003 ;{ }^{\star \star \star \star}$ df $5,20, \mathrm{~F}=2.927064, \mathrm{p}<0.04$.

a Post-hoc comparison to vehicle-vehicle treatment.

Abbreviations as in Figure 2.

baseline and the mean of the 1st and 2nd hours, temperature at sleep onset, maximum temperature over the 6-hour period, and time from drug injection until maximum temperature.

\section{Statistical Analysis}

Data were assessed by one-way ANOVA, using a within groups design for one factor (treatment) with six levels. In those cases in which there were significant 
Table 2. Temperature Variables

\begin{tabular}{|c|c|c|c|}
\hline & Mean & SEM & $\begin{array}{c}\text { Significance } \\
p<\end{array}$ \\
\hline \multicolumn{4}{|c|}{ First hour $\left({ }^{\circ} \mathrm{C}\right)$} \\
\hline VV & 38.83 & 0.49 & NS \\
\hline VL & 39.21 & 0.49 & NS \\
\hline $\mathrm{VH}$ & 39.00 & 0.36 & NS \\
\hline DV & 38.96 & 0.34 & NS \\
\hline DL & 39.23 & 0.34 & NS \\
\hline $\mathrm{DH}$ & 39.03 & 0.30 & NS \\
\hline \multicolumn{4}{|c|}{ Second hour $\left({ }^{\circ} \mathrm{C}\right)$} \\
\hline VV & 39.23 & 0.31 & NS \\
\hline VL & 38.97 & 0.78 & NS \\
\hline $\mathrm{VH}$ & 39.00 & 0.30 & NS \\
\hline DV & 39.25 & 0.36 & NS \\
\hline $\mathrm{DL}$ & 39.35 & 0.30 & NS \\
\hline $\mathrm{DH}$ & 39.26 & 0.35 & NS \\
\hline \multicolumn{4}{|c|}{ Sleep onset $\left({ }^{\circ} \mathrm{C}\right)$} \\
\hline VV & 38.82 & 0.38 & NS \\
\hline VL & 39.06 & 0.37 & NS \\
\hline $\mathrm{VH}$ & 38.69 & 0.37 & NS \\
\hline DV & 39.03 & 0.32 & NS \\
\hline DL & 38.89 & 0.42 & NS \\
\hline $\mathrm{DH}$ & 39.01 & 0.31 & NS \\
\hline \multicolumn{4}{|c|}{ Peak $\left({ }^{\circ} \mathrm{C}\right)$} \\
\hline VV & 39.86 & 0.26 & NS \\
\hline VL & 40.24 & 0.28 & NS \\
\hline $\mathrm{VH}$ & 39.72 & 0.27 & NS \\
\hline DV & 39.80 & 0.33 & NS \\
\hline $\mathrm{DL}$ & 40.00 & 0.31 & NS \\
\hline $\mathrm{DH}$ & 39.86 & 0.30 & NS \\
\hline \multicolumn{4}{|c|}{ Time of peak (min) } \\
\hline VV & 139.54 & 20.87 & NS \\
\hline VL & 152.00 & 20.79 & NS \\
\hline $\mathrm{VH}$ & 190.71 & 25.60 & NS \\
\hline DV & 122.17 & 23.94 & NS \\
\hline DL & 133.46 & 28.30 & NS \\
\hline $\mathrm{DH}$ & 174.27 & 21.27 & NS \\
\hline \multicolumn{4}{|c|}{ First 6 hours $\left({ }^{\circ} \mathrm{C}\right)$} \\
\hline VV & 39.07 & 0.35 & NS \\
\hline VL & 38.95 & 0.55 & NS \\
\hline $\mathrm{VH}$ & 38.95 & 0.34 & NS \\
\hline DV & 39.13 & 0.39 & NS \\
\hline DL & 39.27 & 0.32 & NS \\
\hline $\mathrm{DH}$ & 39.12 & 0.31 & NS \\
\hline \multicolumn{4}{|c|}{$\begin{array}{l}\text { Baseline minus first } \\
\text { hour }\left({ }^{\circ} \mathrm{C}\right)\end{array}$} \\
\hline VV & -0.93 & 0.14 & NS \\
\hline VL & -1.13 & 0.15 & NS \\
\hline $\mathrm{VH}$ & -0.99 & 0.15 & NS \\
\hline DV & -0.96 & 0.12 & NS \\
\hline $\mathrm{DL}$ & -1.15 & 0.14 & NS \\
\hline $\mathrm{DH}$ & -0.97 & 0.15 & NS \\
\hline
\end{tabular}

main effects, post-hoc testing to compare the vehicle condition with various treatments was performed using the least-significant difference test. Analyses of variance were also performed in which the sequence of drug administration was the independent variable and total sleep time and sleep latency were dependent variables; sequence was found to be without significant effect.

\section{RESULTS}

\section{Sleep}

Both doses of triazolam significantly decreased sleep latency (Table 1). Total sleep was increased by both doses of triazolam in the first 2 hours after administration, primarily due to an increase in nonREM sleep (Table 1). There was an overall significant treatment effect for total REM sleep, but post-hoctesting did not reveal that any one group differed from the vehicle-vehicle condition. Rapid-eye movement latency and waking time after initial sleep onset were not systematically affected. Nifedipine alone did not alter sleep latency or total sleep. When both drugs were given in combination, there was no longer a shortening of sleeplatency at both doses of triazolam and no increase in total sleep or nonREM sleep at the higher dose of triazolam.

\section{Core Temperature}

There was no systematic drug effect on core temperature, as assessed by a series of measures including temperature in the 1st or 2nd hours, baseline period minus the 1st hour, mean temperature for 6 hours, peak temperature, time from drug injection until peak temperature, and temperature at sleep onset (Table 2). In all animals combined (regardless of treatment), temperature rose from a baseline of $37.83 \pm 0.25^{\circ} \mathrm{C}$ to a peak of $39.91 \pm 0.08^{\circ} \mathrm{C}(p<0.01)$, after a mean of $152.0 \pm$ 10.6 minutes. Temperature at the time of sleep onset rose slightly above baseline to $38.9 \pm 0.06^{\circ} \mathrm{C}(p<0.01)$. Thus, although specific treatments did not alter core temperature, the act of microinjecting materials into the MPA appears to produce a relatively consistent transient rise in temperature. The core temperature curves for a typical animal appear in Figure 2.

\section{DISCUSSION}

These data confirm our previous report that microinjections of triazolam into the MPA enhance sleep in the rat. The observation that this effect is prevented by the $B Z$ receptor blocker RO 15-1788 (Mendelson and Martin 1992) indicates that it is specific for interaction with the $B Z$ recognition site. The mechanism of action by which triazolam injections into the MPA enhance sleep remains unclear. One possibility that needs to be considered is whether the sleep changes are an indirect consequence of drug-induced changes in core temperature, or whether they represent some more "direct" effect on sleep. The data reported here confirm our previous study, which showed that although injection of all compounds (including vehicle) into the MPA caused a transient rise in core temperature, there were no drug. specific temperature effects. Thus, it seems unlikely that 

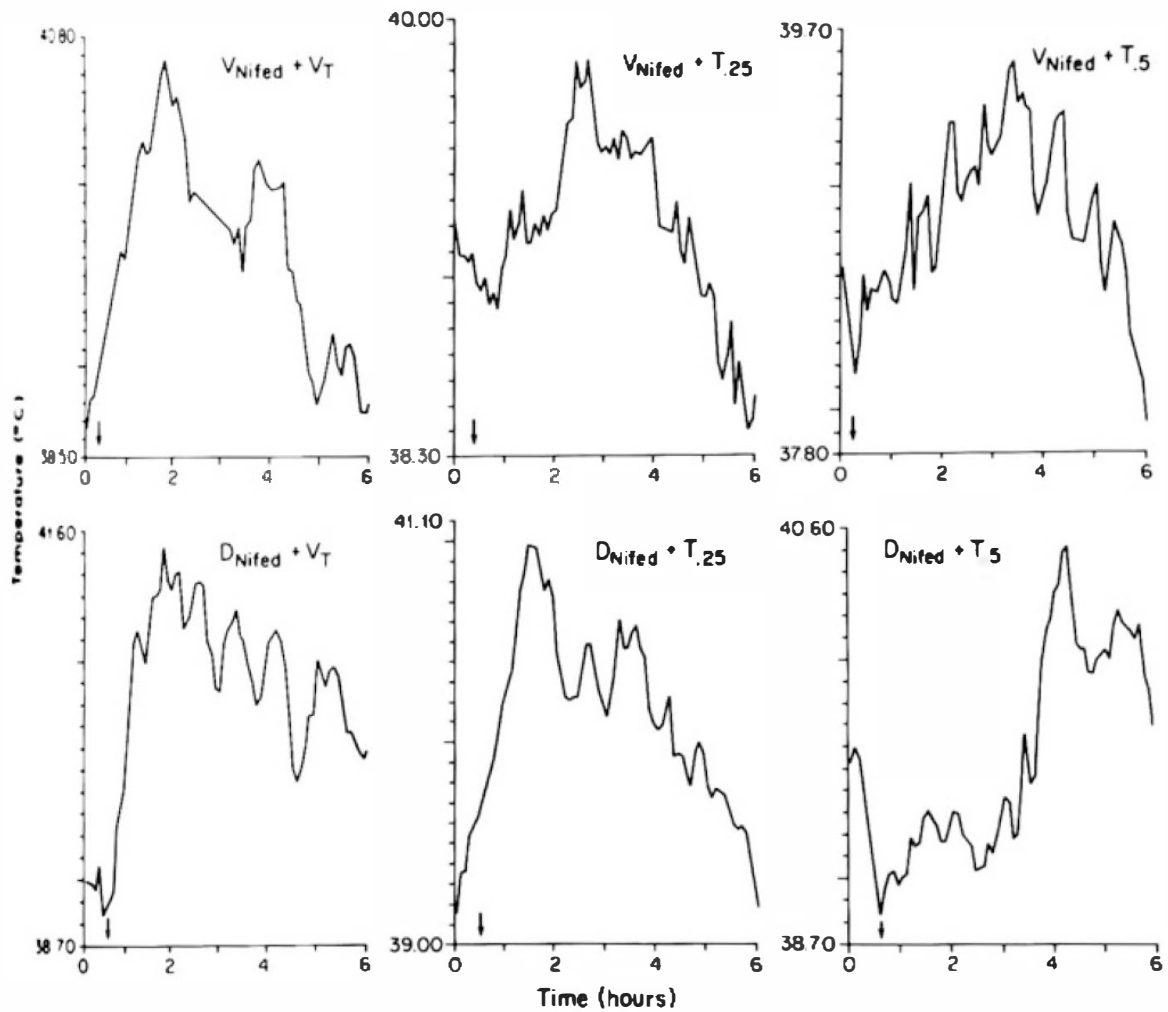

Figure 2. Typical core temperature curves of a rat receiving all six treatments. There was no significant drug effect on temperature (Table 2), and all groups had a similar transient increase in core temperature. It should be noted that the computer program that generates these curves uses automatic scaling, such that the scaling differs slightly in the different conditions. Abbreviations: $\mathrm{V}=$ vehicle; $\mathrm{D}=$ active drug; Nifed. = nifedipine; and $\mathrm{T}=$ triazolam. increases in sleep due to triazolam injections into the MPA are secondary to effects on core temperature. The possibility remains open, of course, that more subtle boal changes in temperature might be observed with hypothalamic temperature probes.

Although more of the interest in the effects of BZ on transmembrane ion flux have focused on its wellrecognized action on the chloride ionophore, there has atso been a persistent interest in possible interaction with calcium ion channel function. In vitro studies have indicated that $1 \mu \mathrm{mol}$ of diazepam alters ${ }^{45} \mathrm{CA}^{++}$uptake into synaptosomes under depolarized conditions in a concentration-dependent manner (Paul and Skolnick 1982), and this may be prevented by the BZ recognition site blocker CGS8216. The interaction of BZs with aloum channel function is also suggested by the obevation that low concentrations of midazolam increase acium spikes in hippocampal neurons (Carlen et al. 1983). Benzodiazepines are also known to interact with thydropyridines in vivo. Intraventricularly adminitered nifedipine has been found to prevent sleep induction by parenterally administered flurazepam (Mendelson et al. 1984). Conversely, the BAY K 8644, a dihydropyridine that enhances ${ }^{45} \mathrm{CA}^{++}$uptake into gnaptosomes, potentiates the hypnotic effect of flurrepam (Mendelson et al. 1986). Thus, when we oberved a decrease in sleep latency and an increase in drepfollowing injection of a BZ into the MPA, it seemed sppopriate to determine any possible interaction with nifedipine. The observation that sleep induction by tria- zolam injections into the MPA was indeed blocked by nifedipine is consistent with this earlier report.

\section{ACKNOWLEDGMENTS}

The authors appreciate the excellent technical assistance of Mr. Simcha Barak and Ms. Yelena Altshuller. This study was partially supported by National Science Foundation Award IBN 8919229 and a grant from the Upjohn Co.

\section{REFERENCES}

Carlen P, Gurevich N, Polc P (1983); Low-dose benzodiazepine neuronal inhibition: Enhanced calcium-mediated $\mathrm{K}^{+}$conductance. Brain Res 271:358-384

Mendelson WB (1987): Human Sleep: Research and Clinical Care. New York, Elsevier, pp 117-118

Mendelson WB, Guthrie RD, Frederick G, Wyatt RJ (1974): The flower pot technique of rapid eye movement (REM) sleep deprivation. Pharmacol Biochem Behav 2:553-556

Mendelson WB, Majchrowicz E, Mirmirani N, Dawson S, Gillin JC, and Wyatt RJ (1978): Sleep during chronic ethanol administration and withdrawal in rats. J Stud Alcohol 39:1213-1223

Mendelson WB, Skolnick P, Martin JV, Luu MD, Wagner R, Paul SM (1984a): Diazepam-stimulated increases in the synaptosomal uptake of ${ }^{45} \mathrm{Ca}^{2+}$ reversal by dihydropyridine calcium channel antagonists. Eur J Pharmacol 104:181-183 
Mendelson WB, Owen C, Skolnick P, Paul SM, Martin JV, Ko G, Wagner R (1984b): Nifedipine blocks sleep induction by flurazepam in the rat. Sleep 7:64-68

Mendelson WB (1992): Characterization of the hypnotic effects of triazolam microinjections into the medial preoptic area. Life Sci 50:1117-1128

Mendelson WB, Martin JV (1992): Characterization of the hypnotic effects of triazolam microinjections into the medial preoptic area. Life Sci 50:1117-1128

Middlemiss DN, Spedding M (1985): A functional correlate for the dihydropyridine binding site in rat brain. Nature 314:94-96

Myers RD (1966): Injection of solutions into cerebral tissue: Relation between volume and diffusion. Physiol Behav 1:171-174

Paul SM, Skolnick P (1982): Comparative neuropharmacology of antianxiety drugs. Pharmacol Biochem Behav 17:37-41

Paxinos G, Watson C (1986): The Rat Brain in Stereotaxic Coordinates. London, Academic Press 